\title{
La obra gráfica de Copi: vanguardia, política y exilio
}

\section{The graphic work of Copy: avant-garde, politics and exile}

\author{
Laura Vázquez \\ Universidad de Buenos Aires-CONICET \\ lauravanevaz@gmail.com
}

\begin{abstract}
- Resumen
La importancia central de la obra historietística de Raúl Damonde Taborda (COPI) reside en la condición paradigmática de su producción en el campo de la narrativa dibujada. Obviamente que este trabajo no puede suplir un estudio que requeriría de una investigación profunda y sistemática, sin embargo, entiendo que puede fijar algunos ejes productivos para futuros análisis. El ensayo pretende, por un lado, recorrer la producción historietística del autor publicada en distintos medios gráficos trazando un período que va desde el exilio político hasta un "quiebre" en su trayectoria artística. Por último, cabe resaltar que la obra gráfica del autor es fundamental no sólo para profundizar los estudios sobre el campo de la historieta y el humor gráfico sino también, para pensar cuestiones más amplias. Dicho en otros términos: su producción resulta peculiar no sólo porque habilita el análisis de un tipo de alegorización particular, sino porque en ese mismo gesto, se trasciende a sí misma.
\end{abstract}

Palabras clave: historieta, arte, exilio, política e industria.

\section{Abstract}

The central importance of the Raúl Damonde Taborda (COPI) comic work, resides in the paradigmatic condition of its production in the comic field. Obviously, this work cannot replace a proper study that would require of a deep and systematic investigation, nevertheless, I understand that it can establish some productive axes for future analyses. This paper tries, on one hand, to analyze the comic production of an author, which was published in different graphical media, taking a broad view over a period that starts in his political exile and ends in a breakthrough in his artistic trajectory. Finally, it is important to stand out that the graphical work of the author is fundamental not only to deep in the studies about comic field, and graphic humor, but also to think about bigger subjects. In other words: its production is peculiar not only because it allows the analysis of a type of particular allegory, but because in that same gesture, it transcends itself.

Keywords: comics, art, exile, politics and industry. 


\section{Copi (right)}

Como punto de partida, es conveniente destacar que el tema de este trabajo está articulado directamente con un eje de mi tesis de doctorado: Oficio, Arte y Mercado: historia de la historieta argentina desde 1968 hasta $1984 .{ }^{1}$ Durante ese recorrido el objetivo fue dar cuenta de la evolución de la historieta argentina y su relación con otras zonas de la industria cultural. Si bien el interés fue realizar un aporte a los estudios en comunicación y cultura, la investigación se recortó sobre un campo de análisis y un trasfondo teórico más específico: una historia de los medios de comunicación que tuvo como objeto a la historieta pero siempre en diálogo con series y procesos más amplios ${ }^{2}$

El interés que reviste la obra de Copi se centra en la disolución de las fronteras al interior de su producción artística. Es esa resistencia al ordenamiento, esa incomodidad frente a la definición, la que provoca el análisis. En este sentido, entiendo que el cruce de líneas (entre el teatro, el comic y la literatura) invita a una reflexión más aguda y crítica sobre la inserción del autor en el campo de la "narrativa dibujada". (Masotta, 1982:10) Dicho en otros términos: la producción de Copi permite indagar de manera significativa la trama significante que emerge del encuentro de dos registros: la escritura y el dibujo. ${ }^{3}$

Al mismo tiempo, el recorte de análisis de este trabajo se centra, fundamentalmente, en un bloque temporal que se extiende desde la segunda mitad de los cincuenta y llega hasta los primeros años setentas y que puede caracterizarse por la percepción unánime del cambio y de una temporalidad acelerada. (Sigal, 1991; Jameson, 1997)

El trabajo pretende, por un lado, recorrer la producción historietística del autor publicada en distintos medios gráficos trazando un arco que va desde el exilio hasta lo que entiendo como un "momento de inflexión" en su trayectoria artística. Por otro lado, la periodización supone, también, una hipótesis de trabajo. El tramo histórico 55-70 coincide con una serie de acontecimientos en la historia política y cultural argentina, de allí que mi objetivo es interpretar la obra de Copi no sólo en su especificidad estética sino también en tanto documento de época. Esta perspectiva dará cuenta de distintos desplazamientos entre la vanguardia y la política, la industria cultural y el arte.

Ahora bien, el recorte temporal del análisis recorre un arco entre dos ciudades, Buenos Aires y París y, al mismo tiempo, supone un quiebre en la producción historietística del autor.

1. Tesis presentada en la Facultad de Ciencias Sociales, Universidad de Buenos Aires. Septiembre de 2008.

2. Conviene destacar que el análisis del lenguaje historietístico y sus cruces con otros medios narrativos, se encuentra aún muy poco desarrollado frente a otras áreas del conocimiento. Obviamente que este artículo no puede suplir un estudio que requeriría de una investigación profunda y sistemática, sin embargo, entiendo que puede fijar algunos ejes productivos para futuros análisis.

3. Para ello parto del planteo teórico-metodológico de Louis Marin (1993) y Roger Chartier (1996) sobre la irreductibilidad del significado entre textos e imágenes. 
El primer tramo está trazado por los años 1955-1962, años en los que resaltan sus tempranas incursiones en el periódico Tribuna Popular hasta sus historietas de renovación estilística publicadas en las revistas humorísticas Tía Vicenta y 4 Patas.

El segundo momento, es entendido como el de su "síntesis gráfica" y comprende la publicación de sus tiras en el periódico francés Le Nouvel Observateur (1962) hasta el estreno de su obra teatral Eva Perón (1970). Este último evento, realizado en un teatro del circuito alternativo parisino, concluye en un atentado terrorista, el control policial y la censura. ${ }^{4}$ Representante de un drama de identidad nacional y de un drama sexual, en la pieza teatral referida, la política se escenifica bajo las formas de un escándalo histórico. Por esta obra, la primera escrita en el exilio, Copi no pudo regresar a la Argentina hasta 1984.

Lejos de entender el corte histórico como una ruptura me interesa más bien, en un gesto contrario, leer las continuidades. Poner en escena las articulaciones en el recorrido artístico y en el tratamiento de los lenguajes y dispositivos: teatro, cómic y literatura. En este sentido, es que encuentro que la comparación entre las condiciones de producción y circulación de su obra, podría aportar una mirada más densa no sólo acerca de su itinerario biográfico sino también, y fundamentalmente, sobre la compleja relación entre cultura de masas y vanguardia.

El bloque 68/69, se trata de un momento iridiscente del campo artístico e intelectual argentino sensibilizado por sucesivos reposicionamientos y quiebres. Rasgoscomola necesidad de transgredir los límites entre la vida y el arte, el antiintelectualismo, el antiinstitucionalismo, el deseo de ampliar el público, de redefinir el concepto de obra de arte con materiales novedosos y el intento de ligar a la política con el arte, están presentes de manera recurrente. En medio de esta coyuntura, un sector de la crítica cultural encuentra en la historieta un objeto de investigación y un medio privilegiado para la intervención teórica. La obra gráfica de Copi debe vincularse, precisamente, en esa intersección: una zona de diálogo entre la vanguardia artística, el interés por los medios y la política a finales de la década del sesenta.

De allí que su trabajo y su posición en el campo, puedan ser leídas como un emergente de las condiciones de producción de la etapa, en un marco de complejización del campo cultural. ${ }^{5}$ Sin embargo, es significativo que los estudios realizados hasta el momento sobre Copi (Aira: 1991; Amícola: 2000; Rosenzvaig: 2003; Link: 2003; Sarlo: 2003) se han concentrado en su actividad como dramaturgo y escritor quedando de este modo relegada la producción gráfica del autor.

4. Su obra Eva Perón (1969) fue la primera escrita en el exilio y su segunda pieza escrita en francés, aunque pareciera pensada en lunfardo rioplatense. Su estreno tuvo lugar el 2 de marzo de 1970 en el teatro L' Epée-deBois, una mínima sala de teatro, posteriormente demolida.

5. La noción de "arte relacional" propuesta por Nicolás Bourriaud (2006) resulta interesante para pensar la movilidad /inscripción de la obra de Copi en el contexto del campo artístico de finales de los sesenta.. (Bourriaud, 2006: 51) Precisamente, la producción de Copi puede leerse en el marco de las prácticas de expansión de los límites del campo artístico que tuvo lugar en el contexto de una trama cultural amplia. 
El dato no es azaroso. Estas perspectivas están vinculadas al lugar de inscripción teórica y disciplinaria (la literatura, el teatro, la crítica cultural) de las investigaciones realizadas hasta el momento. Pero por otro lado, y de manera más decisiva, también cabe pensar que el rasgo está sujeto a la ausencia de un campo consolidado de estudio sobre historietas y humor gráfico. En este sentido, en futuros abordajes, sería productivo analizar las historietas de Copi publicadas en medios nacionales y extranjeros para reconstruir de manera cabal su itinerario.

Asimismo, cabe destacar que aunque los estudios realizados sobre la vida y obra del autor insisten sistemáticamente en resaltar el "carácter inclasificable" de su obra artística (Aira: 1991; Amícola: 2000; Rosenzvaig: 2003; Link: 2003), por otro lado han tendido a la categorización de su obra a un lado u otro de su producción. De allí que los conceptos se han fijado de manera pendular: o se ha resaltado el "carácter híbrido" de su expresión o se ha ponderado cierta zona de su producción sobre las otras: "teatro dibujado", "teatro cómic" y "novela cómic" (Rosenzvaig, 2003); "escritor insólito” (Jitrik, 2003); “Copi no sabe dibujar” (Aira, 1991).

Me interesa discutir algunas de estas afirmaciones e inscribir la obra gráfica del autor en la corriente de autores (Landrú, Oski, Quino, Kalondi, Catú y Brascó) que, entre la segunda mitad de la década cincuenta y la primera mitad de los sesenta, renuevan estilística y temáticamente el campo de humor gráfico en la Argentina. Estos antecedentes que también construyen un nuevo público a partir de nuevas convenciones humorísticas, ya han sido trabajados rigurosamente por: Masotta, (1966; 1982), Rivera (1972; 1976; 1981), Steimberg (1972; 1977), Romano (1972) y Sasturain (1995).

Si bien la obra de Copi no es ni exclusivamente teatral, ni literaria, ni historietística, sino que transita por un continuum permanente, me interesa considerar algunos aspectos de su identificación del dibujo con el teatro y su permanencia "en el pasaje" entre ambos. En los dibujos de Copi hay espacios dentro de espacios, representaciones dentro de representaciones. Cada viñeta propone un núcleo de significaciones que se quedan ahí: entre el tiempo "encapsulado" en cada cuadro y la velocidad de la narración. Su arte está precisamente ahí, en ese durante: entre el dibujo y el texto. Pero no es el dibujo subsidiario de su literatura, por el contrario, es el trazo de sus incursiones gráficas, la rúbrica permanente de su obra.

$\mathrm{Y}$ es que antes que nada, Copi es un dibujante. A partir de allí, despliega un universo transpositivo que no respeta frontera alguna entre géneros ni límite entre lenguajes o espacios de inserción. Retomando la expresión de Michel de Certeau podemos considerar que Copi es "un inquilino de la cultura" (de Certeau, 1999: 24) en tanto habita las circunstancias que el presente le ofrece para transformar el contexto de su vida (su relación con el mundo sensible o conceptual) en un universo duradero. 


\section{La teatralidad de la historieta}

Jamás me interesó el cine. Es un teatro muy imperfecto. Copi

Casi no hace falta decir que el humor de Copi es extravagante, pero si es útil considerar porqué sus historietas constituyen una obra de vanguardia. Partamos de una referencia: Copi fue un exiliado hasta 1984. Raúl Damonde Taborda nació en Buenos Aires, en 1939 y murió en París, víctima de Sida, el 14 de diciembre de 1987. En 1962 se instaló definitivamente en esa ciudad; volvería a Buenos Aires en dos oportunidades, en 1968 y poco antes de morir. Conviene subrayar que la palabra "exilio" es un concepto polisémico y ambiguo. Siguiendo a Marina Franco:

es importante evitar el uso de categorías totalizantes como "el exilio argentino" (excepto para designar unaidentidad autoatribuida porlos propios actores) yutilizar, en cambio, el término plural "exiliados" o "distintos sectores de argentinos en el exilio" (y sólo cuando la autorrepresentación de los actores lo indica). Esta opción está vinculada al carácter heterogéneo del fenómeno emigratorio, tanto en un sentido sociocultural como político-ideológico. Así, una denominación plural permite evitar los riesgos de construir un conjunto homogéneo deificado, cuyo único efecto sería encubrir y reducir la diversidad de sujetos y experiencias. (Franco, 2008: 19)

Los motivos de partida son uno de los aspectos más complejos de definir porque ello afecta la definición misma de exilio y la identificación del emigrado como exiliado. Cabe distinguir el peso de los factores emocionales para explicar no sólo una serie de experiencias de exilio, sino los rasgos de las prácticas políticas previas. Este énfasis no significa un vaciamiento del sentido político de la experiencia, sino redescubrir en ella la complejidad e imbricación de las dimensiones, en definitiva, el carácter global de esa situación. En la trayectoria de Copi esta experiencia produjo un "quiebre" o punto de inflexión que deja "marcas" en sus textos y dibujos. En distintos pasajes de su producción, esa experiencia es representada a partir de tensiones pasadas y presentes. Se trata de la evocación de un tema siempre emergente, un nudo constitutivo de su historia como sujeto:

Soy viejo y mirón. Mi voz asume la forma de escenas fugaces, como el amor bajo el golpe de una reverberación o una muerte fatal. Condicionado por la sensibilidad del Río de la Plata, conservo la exigüidad de la escenografía. Los viajes me han enseñado que unas pocas ropas bien elegidas bastan para dar seguridad y buen crédito al exiliado. ¿Exiliado? La palabra ha salido sola de mi bolígrafo, seguida por un signo de interrogación. Si alguna vez debiera decir lo que sea sobre el exilio, me cuidaría muy bien de escribir en primera persona. Y si es verdad que he tenido miedo de poner los pies en la Argentina después de 1969, eso ya no me sucede más. ${ }^{6}$

6. "El exilio”, Del prólogo de una novela que iba a titularse El Río de la Plata y que Copi dejó inconclusa. Tra- 
Su padre, Raúl Damonte Taborda, tuvo una prominente y controvertida actuación política; también era pintor y periodista. Fue un político radical, diputado nacional en 1938 y una de las figuras del frente político-intelectual del antifascismo argentino (Tarcus, 2001). Su madre era la hija menor de Natalio Botana (fundador y propietario del diario Crítica); la esposa de éste, Salvadora Onrubias, anarquista feminista, fue dramaturga y tuvo influencia sobre su nieto (en varias de sus historias Copi la retrata como "una anciana erotómana"). ${ }^{7}$ Los Damonte se exiliaron en el Uruguay tras el ascenso de Perón, con el que Raúl Damonte rompió su vínculo después de haber pertenecido a su círculo más próximo. Copi re-presenta el exilio en su itinerario biográfico:

La distancia y la ironía con las que pienso el Río de la Plata -que después de todo es mi lugar natal-son sentimientos recientes. Fue durante los años de prohibición que escribía mis grandes dramas. Mi escritura fue entonces más argentina que nunca. La persecución de mis hermanos, la muerte violenta de algunas personas próximas a mi familia, me hicieron imaginar el Río de la Plata como un Purgatorio del que había escapado sintiéndome culpable. No tenía ni un rasguño, aparte de los del alma. Me pregunto qué habría sido de mi vida en Buenos Aires si el azar no hubiera hecho que, a la edad de veintidós años, mientras pasaba mis vacaciones en París, mi padre no hubiera pedido asilo en la embajada uruguaya, perseguido por ya no recuerdo cuál régimen. (Copi, ídem.)

En este contexto y en los primeros años de los sesenta, las publicaciones humorísticas atravesaban por un momento de decadencia en las ventas pero excepcionalmente esplendorosa en estilos, diversificación y novedades. Atrás había quedado la denominada "edad de oro" del campo y el auge en las ventas de revistas populares como Rico Tipo o Patoruzito. Por entonces, la clase media intelectual argentina (conformada como "nuevo público") redescubre la potencialidad del género:

Los complejos altibajos de los '60 marcarán como una zona de fractura y replanteo a este panorama, determinando en la década siguiente una nueva relación entre texto e imagen, más despegada y creativa que en la etapa anterior. Irrumpe, en este nuevo escenario, un público inédito, que traslada o exige sus propias convenciones culturales y estéticas, pero también, desde luego, una nueva promoción de dibujantes y guionistas que hacen lo propio, determinando la emergencia de pautas, productos y reglas de juego no advertidas (Rivera, 1992: 58)

En este marco, revistas como Panorama, Confirmado o Primera Plana incorporaron regularmente en sus páginas tiras de los jóvenes dibujantes (las "nuevas promesas") del

ducción realizada por Tomás Eloy Martínez. Citado en: Tcherkaski, 1998: 134.

7. De la historia de los Botana en la historia reciente argentina, hay un relato "excéntrico" y atractivo en las memorias del tío de Copi, Helvio Botana (1985). 
mercado editorial: Oski, Caloi, Quino, Copi y Kalondi. De manera paradigmática surge Tía Vicenta (1957-1966) una revista precursora en imponer un nuevo estilo humorístico y que reúne a la nueva generación de profesionales. Justamente, Copi desde muy joven colaboró en la publicación intensivamente. Por una disparidad de opiniones, Carlos Peralta (Del Peral), Secretario de Redacción de Tía Vicenta, funda su propia revista: 4 Patas (1960). Copi, junto a otros dibujantes, decide sumarse al nuevo proyecto. El experimento editorial dura sólo cuatro números, hasta su clausura política. En esta revista, Copi "se da el gusto" de escribir textos experimentales y críticos:

"Je vous" remercie d' abord las orquídeas que me envió: mamá adora las orquídeas. La pobre esta tan vieja que no puede masticar otra cosa. Usted pensará que somos una familia de excéntricos, y en parte es cierto, pero lo principal - ¡usted estará de acuerdo conmigo!- es estar fuera de moda: ¡ahora todo el mundo está a la moda! Mamá misma, sin ir más lejos, se está poniendo tan comunista. Me pide de rodillas que le compre una de esas nuevas pelucas gonflées. Dice que se tiene que pasar todo el día cubriéndose la calva con las manos para que no se hiele, y de esa manera no le queda ninguna mano libre para pedir limosna. Pero yo, mon cher, como usted comprenderá, me mantengo inflexible con respecto a ese punto. Como una gran concesión le permitiría tener una mano nueva, pero una peluca ijamás! ${ }^{8}$

Su atípica herencia familiar junto a los acontecimientos políticos de la época, constituyeron para el joven Copi los materiales de la obra que desarrolla en París, a principios de los sesenta. La experiencia periodística junto a su padre (el trazado de sus primeras y mordaces caricaturas) marcó una visión barroca, extrema y acelerada. El primer personaje que creó durante esos años fue “Gastón, el perro oligarca”, que se publicó en entregas sucesivas en el diario Tribuna Popular. Esta historieta le permitió desplegar una crítica a la ideología conservadora del gobierno militar de la llamada "Revolución Libertadora". Uno de los blancos predilectos fue el presidente de facto Pedro Aramburu y su vice Rojas, muchas veces dibujados como Luis XVI y María Antonieta, con los atuendos y los símbolos de la monarquía.

Esta narrativa gráfica establece algunos parámetros que evocan los gestos de la vanguardia artística porteña de los años sesenta. Los dibujos mínimos constituyen un boceto ligero y audaz de una escritura densa y opaca. Se trata de un trabajo de ruptura en lo que concierne a los elementos gráficos de la historieta tradicional. ${ }^{9}$ Aparentemente sencillas cada imagen esconde una complejidad inabordable.

8. Para la reproducción completa de la carta publicada en 4 Patas (julio de 1960) ver: Rivera, 1981: 44-45.

9. Tomo la concepción del fenómeno de "ruptura" del trabajo de Jitrik, 1996: 11-28. 
Las líneas gráficas de una viñeta paralizan el relato. La fecundidad está en el tránsito de la literatura a la historieta y de la historieta a la literatura, en el medio, y como un elemento vector: una puesta en escena de personajes bidimensionales y voluminosos, absurdos y lógicos. Compuestos por líneas veloces y hasta "descuidadas" los dibujos componen una estética de vanguardia. Y es que Copi no dibuja "personajes", dibuja actores, travistiendo los límites mismos del lenguaje.

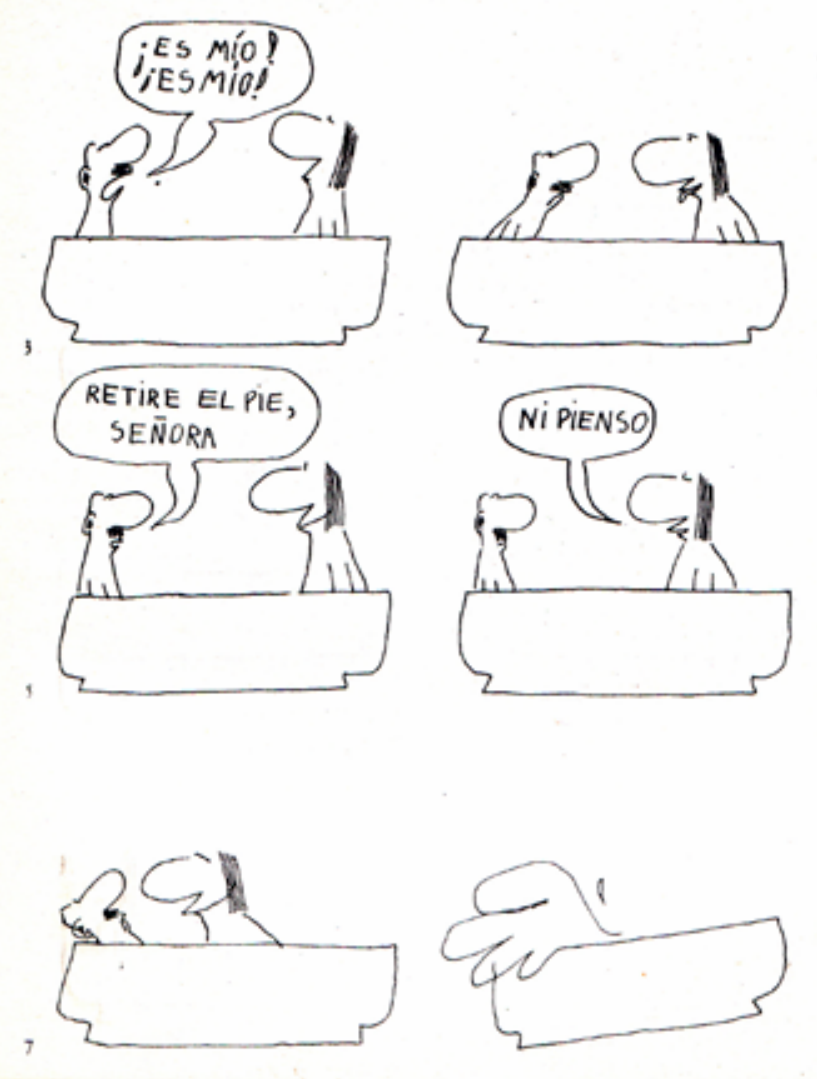

\section{Los pollos no tienen silla $(1968)$}

136 Durante la segunda mitad de los sesenta, triunfa en Francia como dibujante de cómics. A finales de los sesenta, parte de su producción es traducida y editada en la Argentina. El efímero semanario La Hipotenusa, reedita hacia 1967 las tiras que Copi ya había realizado para Le Nouvel Observateur. La edición de una de sus historietas en LD (Literatura Dibujada, 1969) y la compilación que realiza el editor Jorge Álvarez bajo el título, "Los pollos no tienen silla" (1968) es el material que circula por entonces en las librerías de Buenos Aires. Más adelante, otra de sus célebres historietas, fue compilada y traducida por Anagrama (Barcelona, 1982) bajo el título Las viejas putas, la serie fue publicada originalmente en 1977 (París, Editions du Square). 
Entiendo que este interés no es aleatorio sino que tiene una correlación directa con la emergencia de un discurso crítico sobre la cultura de masas, la impronta de la modernización cultural y la articulación entre producción artística y teórica a finales de la década del sesenta. Precisamente, y de manera paralela, durante la etapa se asiste a una revalorización del humor gráfico con epicentro en revistas especializadas y en instituciones como el Instituto Di Tella. De manera significativa, la realización de la "Primera Bienal Internacional de la Historieta" celebrada en el Di Tella revela hasta qué punto para algunos críticos, artistas e intelectuales, el medio resultaba un espacio susceptible para el análisis sociológico y la crítica cultural.
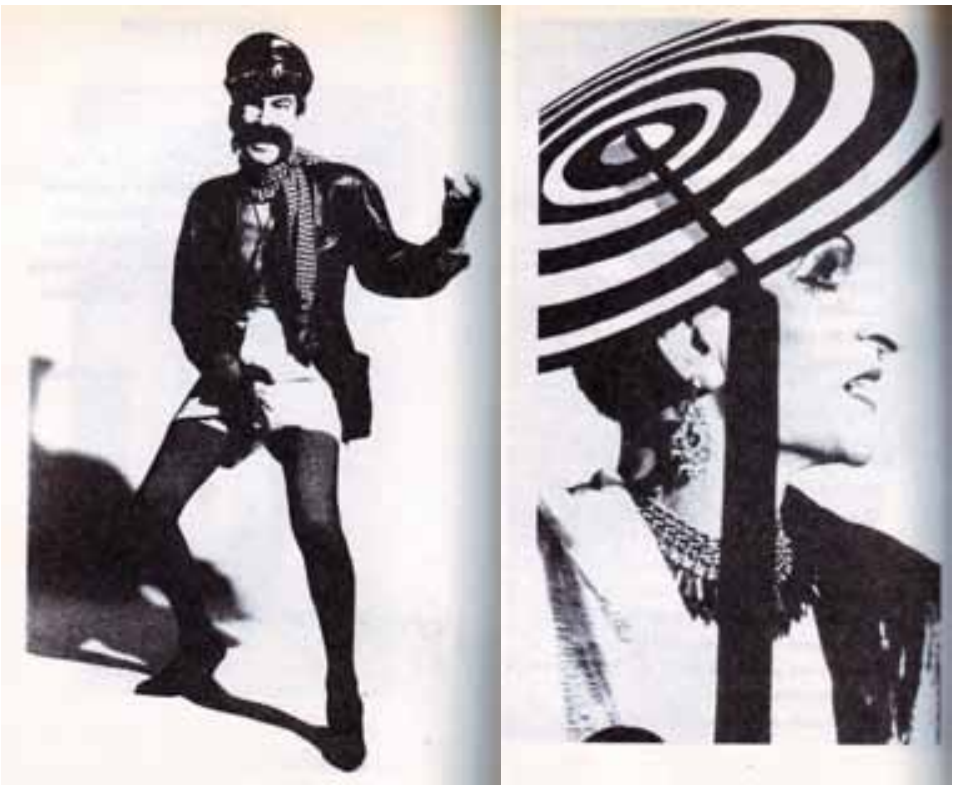

Específicamente, desde 15 de octubre al 15 de noviembre de 1968 se realizó en el Di Tella, la "Primera Bienal Mundial de la Historieta". El evento fue organizado de manera conjunta entre el Instituto Torcuato Di Tella bajo la dirección de Enrique Oteiza y la Escuela Panamericana de Arte, presidida por David Lipszyc. Se encomendó la organización y codirección del proyecto a Oscar Masotta. La realización de la muestra tuvo lugar en la sala del Centro de Artes Visuales del Instituto, bajo la dirección de Jorge Romero Brest. La Bienal retoma, fundamentalmente, los objetivos y propósitos centrales de la exposición internacional titulada "Bande dessinée et figuration narrative”, realizada en el Musée des Arts Décoratifs del Palacio del Louvre, durante los meses de abril a junio de 1967. La tarea llevada adelante por Oscar Masotta en estos años, es de una importancia crucial para entender la aproximación entre historieta, arte y vanguardia. ${ }^{10}$

10. Para una aproximación a la trayectoria de Masotta al término de los sesenta se recomienda especialmente ver el trabajo de Ana Longoni (2004). 
A partir de su residencia permanente en Francia, además de consolidarse como un prolífico dibujante de cómics (aunque comenzara vendiendo sus dibujos en las calles), Copi se integra a la bohemia y a las experiencias estéticas del Grupo Pánico, un colectivo fundado por el español Fernando Arrabal, el chileno Alejandro Jorodowsky y el francés Roland Topor. Paralelamente a la incorporación de Copi al grupo, se suman Víctor García, Jorge Lavelli y Jérome Savary. El programa de acciones teatrales y experimentación artística, fue denominado "Los Efímeros Pánicos” y estuvieron basadas en la improvisación a partir de un esquema argumental mínimo. Siguiendo a Daniel Link:

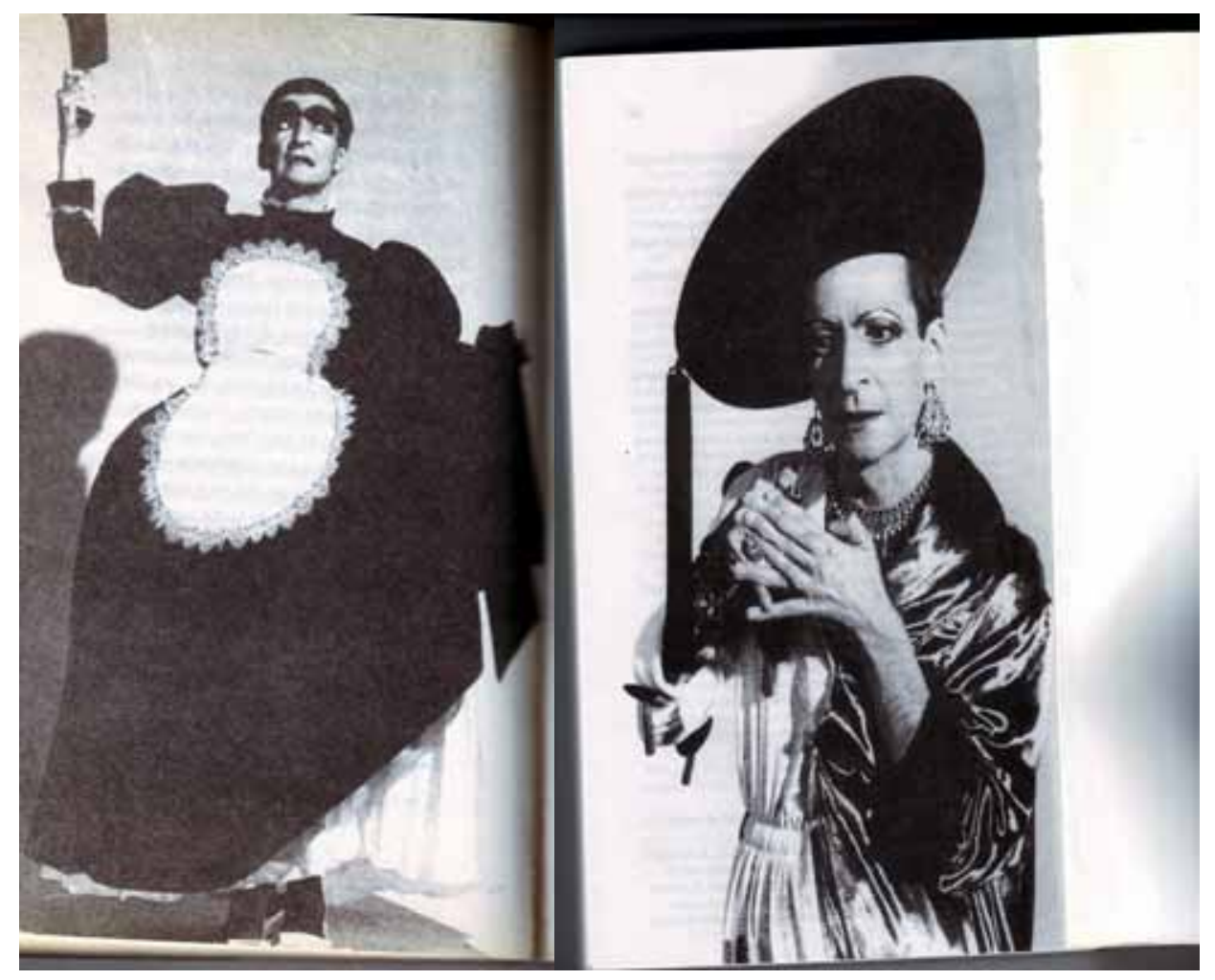

la profusión de utilería (instrumentos de odontología, miles de muñecas desmembradas, pedazos de carne) terminaba repartiéndose entre el público. A la obsesión temática por el freak y a la idea de celebración colectiva se sumaba, pues, toda una economía del don. (Link, 2003: 106)

Por entonces, experimenta el travestismo escénico, actúa en roles protagónicos, y construye un arte del absurdo. El escenario no podría ser más apropiado ya que abundan por entonces en París las revistas satíricas y los espectáculos de café concert; Copi elige sus objetos de escarnio: la prepotencia sexista, la intolerancia moral, y la homofobia. De esta manera, entiende al teatro como desmesura, lo efímero del instante caricaturesco: 
Si el teatro es un espejo ilusorio, algo tan real como irreal que reproduce la vida sin ser la vida, nada más teatral que un travesti. Construido con maquillajes y postizos actuando aquello que no es, sin dejar de serlo, un espejo dentro del gran espejo teatral, una imagen refractaria. (Rosenzvaig, 2003: 126)

\section{Dramaturgia}

Escribió un total de dieciséis obras teatrales, incluyendo un sainete en verso. Con excepción de Un ángel para la señorita Lisca (1962) once de sus piezas teatrales no fueron estrenadas en la Argentina, sino hasta después de su muerte. Las obras estrenadas en el país fueron: La noche de la rata (1991), Una visita inoportuna (1992), La Pirámide (1995), además del sainete en verso Cachafaz (2001).

Ya distinguido como dibujante y dramaturgo, con la novela corta El uruguayo (1972) comienza su carrera de escritor. Publicó cinco novelas: El baile de las locas (1976), La vida es un tango (1979, única que escribió en castellano), La ciudad de las ratas (1979), La Guerre des Pedés (1982, aún sin traducción al castellano) y La Internacional Argentina (1987). Además agrupó sus historias en dos antologías: Las viejas travestis (1978, donde se incluye "El uruguayo") y Virginia Woolf ataca de nuevo (1984).

En la Argentina, el interés que cobra su obra a fines de los sesenta no es de ningún modo fortuito sino que es característico del contacto entre artistas, intelectuales e industria cultural durante el segundo tramo de la década. La popularidad de los medios masivos de comunicación, llamaba la atención a actores tradicionalmente no vinculados a los mismos. Prácticas y objetos no jerarquizados por la alta cultura fueron absorbidos por distintas instituciones.

Fotonovelas, cómics, afiches publicitarios y programas de televisión fueron analizados en su condición de objetos portadores de sentido. Los productos de la cultura de masas dejaron de ser "síntoma social" para pasar a formar parte gradualmente de los llamados por entonces "nuevos lenguajes de masas". Y en este marco, la obra de Copi resultaba óptima para poner a prueba que es posible ir de los medios al arte y del arte a la política.

\section{El fuera de campo}

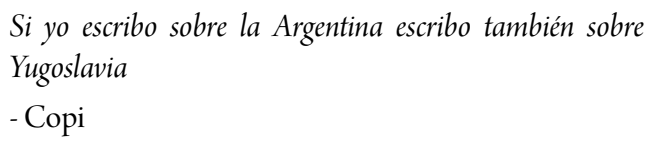

Su tira semanal La mujer sentada fue publicada en Le Nouvel Observateur, en 1964. Con un dibujo audaz y un trazo novedoso (la silla es una continuación gráfica del cuerpo de la protagonista) el humor de vanguardia de Copi produce la ilusión de la sencillez. La mujer sentada, solemne, tosca y descortés es el eje de todos los movimientos que se producen en cada cuadro. Absolutamente efectiva, a pesar de su ociosidad, el personaje encarna la imagen de la tía paralítica del autor, a la 
que según sus palabras: "quiso como a nadie" (Aira, 1991).La mujer sentada es puro movimiento y dinámica; y es precisamente su aparente (¿engañosa?) inmovilidad la que genera la fluidez del relato:

Vine a París para ver teatro. Y me quedé. Mi padre, que me enviaba dinero, estaba asilado en una embajada. Con un amigo vendía dibujos en el Puente de las Artes, pero seguía siendo muy burgués. Fue Martine Barrat quien me acercó al teatro. Me llama un día al Observateur donde yo dibujaba y me dice que quiere hacer La mujer sentada, que había hecho hacer un disfraz de pollo. Fui al Centro Americano donde trabajaba con Graciela Martínez. Le dije: "Si usted quiere le escribo un verdadero sketch”. Martine llamó a Lavelli, que debía hacer la puesta, y a Arrabal, que iba a actuar. Nos conocíamos. Vinieron, nos miramos ... ¿Qué son estos locos? Nos descubrimos argentinos. No había visto argentinos por cuatro años. ${ }^{11}$

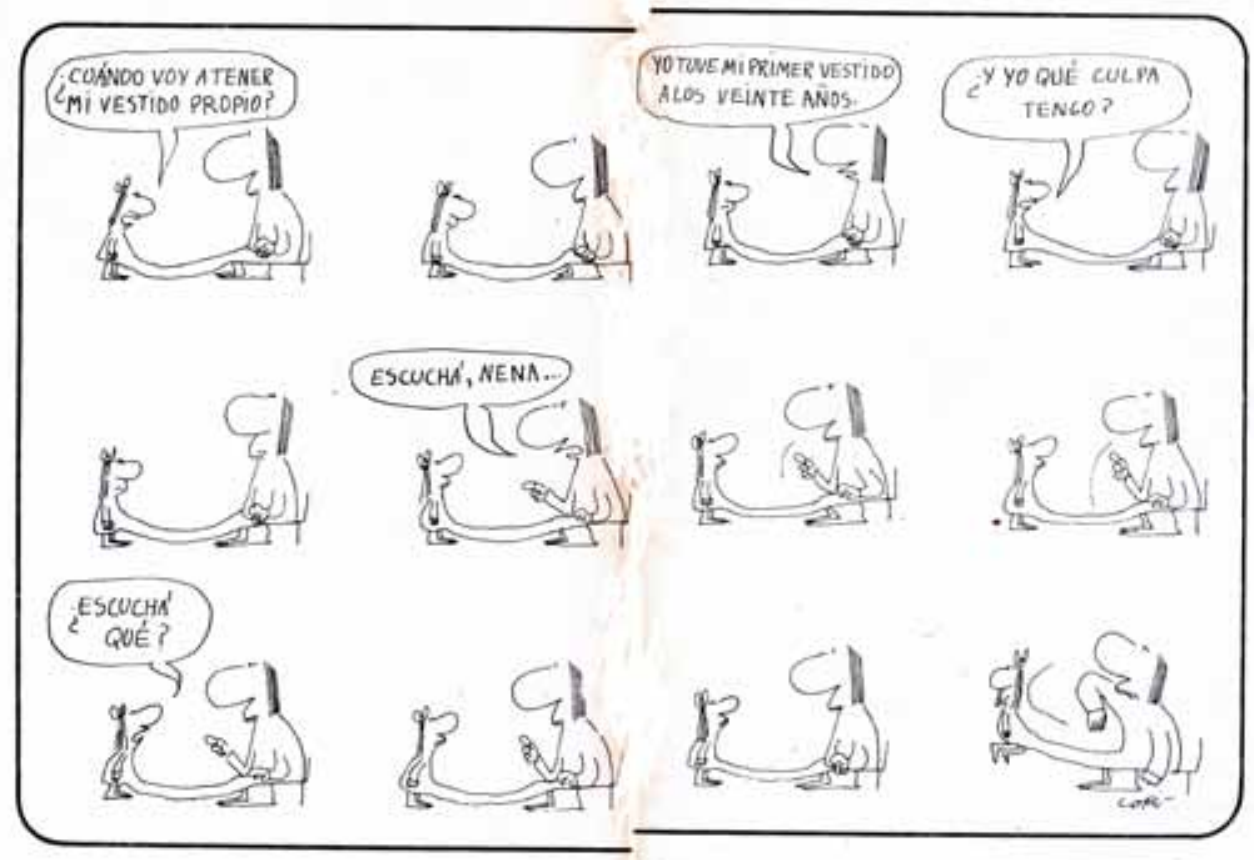

140 Una historia próxima un cómic teatral o una idea que desemboca en cómic. La indefinición del personaje se evidencia cuando la mujer le pregunta: “¿usted es pollo o pato?”. Partamos de una definición convencional sobre el lenguaje historietístico: la historieta nos hace "ver” el tiempo y la suma de los cuadros dibujados, transforma el tiempo en espacio, lo espacializa, y en

11. Copi, “Cada uno debe inventarse sus historias”, entrevista realizada por Libération, reproducida en: Tcherkaski, 1998: 123. 
esa operación lo representa (Gubern, 1973). Y lo interesante entonces, es que las tiras son una puesta en escena, casi una performance, rompiendo con el montaje tradicional. Sus dibujos no tienen el efecto de "lectura del tiempo" sino que el relato está antes que su despliegue.

Anticinematográficos (a contracorriente de la historieta hegemónica) sus cómics rompen con la construcción espacial y temporal de las viñetas y adquieren "un sentido antinarrativo" (Aira, 1991:12). En ellos, no hallamos una sucesión de dibujos para desplegar una historia: en el mundo-dibujo de Copi el tiempo está concentrado. Se aventura a la imperfección, al desenfado, y ese recurso lo salva. Como subraya César Aira: "Toda la obra narrativa de Copi es en cierto modo un umbral entre dibujo y relato" ${ }^{12}$ Su producción no es ni teatral, ni literaria, ni historietística, sino que transita por un continuum dialéctico.

Ante el esquematismo que le impone su trazo, responde con la experimentación del lenguaje gráfico. A partir de "cajas textuales" simula la narración de una historieta. Presenta viñetas allí donde no hay cuadros y desde un dibujo hermético e inclusive monótono hace de la letra un dibujo y utiliza el tiempo narrativo de la secuencia gráfica para contar una historia en pocas escenas. Copi “dibuja con actores” y en el cruce de líneas entre el teatro y la historieta produce un teatro del absurdo y la desmesura. Su obra está precisamente ahí, en el espacio in between que se queda entre el dibujo y la letra:

En la operación de cambio de soporte, de cómic a literatura, se cuela algo nuevo. ¿Qué? Quizás no valga la pena preguntarse por la sustancia de eso nuevo. Quizás es sólo el cambio de soporte mismo, un cambio generalizado. Copi no pasa del dibujo al relato, o viceversa, sino del dibujo o el relato (o el teatro) al cambio de uno al otro, y se queda en el cambio. Con lo que participa de uno de los procesos más fecundos, todavía lejos de agotarse, del arte contemporáneo (Aira, 1991:42)

En Europa, sus dibujos circularon por publicaciones como Twenty y Bizarre, Linus, Hara Kiri y Le Nouvel Observateur. Además de La mujer sentada, inventó otros personajes de historieta: Libérett (para el diario Libération) y Kang, un canguro. Los argumentos de Copi son imposibles de explicar, analizar o siquiera resumir. En palabras de Daniel Link porque son casi imposibles de recordar:

las catástrofes se suceden, los personajes proliferan (liberados de toda carga psicológica) y mutan hasta volverse irreconocibles. En El baile de las locas, por ejemplo, toda está sucediendo en ese Teatro Total de la Homosexualidad a una velocidad de vértigo (travestismo, sadomasoquismo, drogas, casamientos, amputaciones, muertes violentas, resurrecciones), sin otra lógica que la de

12. El libro de César Aira (1991) reúne las cuatro conferencias que dio el escritor en el Centro Cultural Ricardo Rojas, durante el mes de junio de 1988. El ciclo se llamó “Cómo leer a Copi”. Además de este trabajo conviene revisar la tesis de Marcos Rosenzvaig (2003). Finalmente, el lúcido artículo de Daniel Link (2003) Específicamente sobre la obra de teatro Eva Perón, escrita por Copi ver el análisis de Beatriz Sarlo (2003). 
la escritura como un valor puro y, a la vez, político (Link, 2003: 105)

Copi no se coloca ni en el debate intelectual ni en la problematización grave de la moral sexual vigente. Su operación es desacralizadora y crítica, barroca y mutante. Sus historias son fatales: los personajes (crueles y brutales) lindan, muchas veces, con lo grotesco. Tienen una sensibilidad melodramática que desemboca, casi siempre, en el desborde pasional o en la locura.

Me tiende un cuchillito y me pide que se lo hunda en la cadera, lo hago, ella ruge de placer, se acuesta sobre la mesa de la cocina, me pide que le ponga un cepo a la altura del muslo y le cierre la rodilla. No me atrevo, tiemblo. Tómate unas anfetaminas, me dice. Me trago un puñado. Cuéntame cómo has matado a la vieja, me suplica. Invento: Primeramente meé sobre ella, luego le mordí la yugular. Hundo el cuchillo en la rodilla, le separo la rótula, ella aúlla de placer. ¡Córtame el vientre, dice dando alaridos, hazme una cesárea! Pongo a calentar al rojo vivo un cuchillo de cocina, mientras lo caliento voy a buscar un hámster que le meto en el culo, la loca se contorsiona. (El baile de las locas)

Vertiginosos y circenses, están provistos de una racionalidad política. Y es que Copi nunca se interesó por "resolver" el status contradictorio de la historieta sino, por el contrario, optó por afirmar su arte en la paradoja. Sus cómics son tan inclasificables como su teatro o su escritura. Su producción, prácticamente se ubica en un "fuera de campo" de la historieta, pero alcanza para iluminar el mapa de producción de finales de los sesenta; esa impersonalidad más próxima a los estereotipos de la cultura de masas.

\title{
4. A modo de cierre
}

\author{
"Me llamo Raúl Damonte, pero firmo Copi porque \\ así me ha llamado siempre mi madre, no sé por qué" \\ Copi, El baile de las locas
}

Como vimos, la biografía de Copi da por resultado un itinerario muy particular. Este trabajo buscó explorar algunas de las facetas de esa trayectoria, detenerse en ciertos aspectos, escasamente explorados por la bibliografía académica. Su producción artística está atravesada 142 por distintos campos y permite pensar en una producción de mundos incluidos unos en otros. El cataclismo y la desgracia, la transposición de géneros, la carencia del deseo o su abundancia, son tópicos recurrentes en las historias de Copi. La imprecisión organiza la literatura y los dibujos de Copi y, en ese sentido, desafía todo intento de categorización: "valiosa como lo es en sí misma, vale menos que él; o que esa forma de su persona que es su trabajo”. (Aira, 1981:61)

El interés ha sido ubicar la producción de Copi en un debate más amplio que el estudio del campo historietístico, el literario o el teatral. Entiendo que su biografía (de la que no he 
explorado sino algunos aspectos) permite poner en escena de manera paradigmática ciertas transformaciones en la forma de concebir el arte.

En este sentido, un cambio de paradigma no sólo implica transformaciones en la producción de discursos, sino también en la percepción de éstos. El público comienza a ver de otra manera las obras, utiliza otros parámetros (relacionados con la coyuntura histórica y la evolución del género) para evaluarlas; se produce un cambio en el horizonte de expectativas del público (Jauss, 1976: 174 175). En otros términos, Copi es portavoz de un discurso emergente en la historia cultural del período analizado. Como subraya Jorge Rivera, lo que fue actualidad y polémica se convierte en historia de la cultura: “Toda cultura, en definitiva, es historia de sí misma”. (Rivera, 1995: 35)

El debate de las últimas décadas respecto del canon literario discute no sólo la pertinencia de una tradición literaria heredada en los contextos de la sociedad globalizada y multicultural, sino que, en definitiva, cuestiona el lugar que ocupa la literatura entre las demás expresiones y prácticas artísticas. En este sentido, y partiendo de la aproximación de Oscar Masotta sobre la historieta (Masotta, 1982) puede pensarse que la "apertura" del canon literario y el descentramiento de la literatura en tanto práctica simbólica (Link, 2003) permite pensar en una continuidad entre historieta y literatura, arte y mercado, escritura y dibujo antes que en prácticas específicas o fragmentadas.

En el caso de la producción de Copi esta horizontalidad de las prácticas se revela de manera significativa. Como vimos, el carácter polifacético de su arte desemboca en una obra dislocada, casi inaprensible. Su arte está caracterizado por la hibridez y difícilmente pueda encasillarse en un esquema de géneros puros. Su voracidad errática se propuso cuestionar desde la letra y desde el dibujo los sentidos dominantes.

En lugar de fragmentar su biografía en compartimentos en tanto "novelista", "dramaturgo" o "dibujante" mi interés ha sido entender la serie como una dialéctica. Uno de los interrogantes centrales que suscita la producción de Copi gira en torno a la forma material de su obra gráfica. ¿Cómo analizar sus dibujos aparentemente modestos, "escolares” y en el mismo movimiento, experimentales y extremos? Su obra, pero también su inserción en el campo artístico de las décadas del sesenta y setenta, da cuenta de un discurso que rearticula arte y cultura de masas y construye un espacio alternativo.

La superposición de distintos elementos genera un espacio que podría pensarse como heterolingüístico en el que conviven de manera intersticial, la literatura, el teatro, la historieta. La de Copi se trata de una lengua contaminada en la que se entrelazan y llegan a conectarse (pero nunca se superponen totalmente) distintos géneros, campos y discursos. De allí que su obra gráfica genera un espacio de cruce entre la literatura y el teatro pero también de imposibilidad de traducción.

En síntesis, su dibujo se queda en un decir intermedio, transicional y siempre incompleto. Quizás sea esa ilegibilidad de los dibujos de Copi lo que provoque el efecto mayor de su obra. ¿Por qué gustan tanto si son dibujos "menores”, simples e imperfectos? Posiblemente porque nos remiten una y otra vez a los dibujos de nuestra infancia. Experimentales en sí mismos, su 
trazo se entrega al juego evidenciando una gráfica que evidencia la brutal (y extraordinaria) porosidad de los lenguajes.

\section{Referencias bibliográficas}

Aira, C. (1991). Copi. Buenos Aires: Beatriz Viterbo.

Amícola, J. (2000). "Campeones campo: Copi y Perlonguer". En Campo y Posvanguardia, Manifestaciones culturales de un siglo fenecido. Buenos Aires: Paidós.

Bourriaud, N. (2006). Estética relacional. Buenos Aires: Adriana Hidalgo.

Botana, H. (1985). Tras los dientes del perro. Buenos Aires: Peña Lillo.

Chartier, R. (1996). Escribir las prácticas. Foucault, de Certeau, Marin. Buenos Aires: Manantial.

De Certeau, M. (1999). La invención de lo cotidiano. México: Universidad Iberoamericana.

Franco, M. (2008). El exilio. Argentinos en Francia durante la dictadura. Buenos Aires: Siglo XXI.

Gubern, R. (1973). Literatura de la imagen. Barcelona: Salvat.

Jameson, F. (1997). Periodizar los 60. Córdoba: Alción.

Jauss, H. R. (1976). La literatura como provocación. Barcelona: Península.

Jitrik, N. (1996). “No toda es ruptura la de la página escrita”.En Informes para una academia. (La crítica de

la ruptura en la literatura latinoamericana). Buenos Aires: Instituto de Literatura Hispanoamericana,

Facultad de Filosofía y Letras, Universidad de Buenos Aires.

Link, D. (2003, noviembre). “La carne dice”. Zigurat $N^{\circ} 4$.

- (2003). Cómo se lee y otras intervenciones críticas. Buenos Aires: Norma.

Longoni, A. (2004). “Prólogo” y “Oscar Masotta: vanguardia y revolución en los sesenta”.En Revolución en el arte, Pop-art, happenings y arte de los medios en la década del sesenta. Buenos Aires. Edhasa.

Masotta, O. (1966). “Prólogo”. En Técnica de la historieta. Buenos Aires: Escuela Panamericana de Arte. - (1982). La historieta en el mundo moderno. ( $2^{\circ}$ ed.). Buenos Aires: Paidós.

Marin, L. (1993). "L’être del ' image et son efficace”. En Des pouvoirs del 'image. Gloses. Paris: Editions de Minuit.

Rivera, J. B. (1972). "Para una cronología de la historieta”. Historia de la literatura universal. Vol. 14. En Las literaturas marginales. Buenos Aires: CEAL.

_ (1976, febrero y marzo). "Historia del humor gráfico argentino”. I y II. Crisis Nº 34 y N 35, Buenos Aires.

— (1981). "Prólogo". En César Bruto, Landrú, Copi y otros. Humorismo y costumbrismo (19501970). Buenos Aires: CEAL.

- (1992). Panorama de la historieta argentina. Buenos Aires: Coquena Grupo Editor.

Romano, E. (1972). "Examen de la historieta” y "La fotonovela”. Historia de la literatura universal, Vol. 14. Buenos Aires: CEAL.

Rosenzvaig, M. (2003). Copi: sexo y teatralidad. Buenos Aires: Biblos.

Sarlo, B. (2003). "Buscá un vestido, dijo Eva”. En La pasión y la excepción. Buenos Aires: Siglo XXI Editores.

Sasturaín, J. (1995). El domicilio de la aventura. Buenos Aires: Colihue.

Steimberg, O. (1972). “La historieta. Poderes y Límites". Transformaciones N 41. Buenos Aires: Centro Editor de América Latina. 
(1977). Leyendo historietas. Estilos y sentidos de un “arte menor”. Buenos Aires: Nueva Visión. Sigal, S. (1991). Intelectuales y poder en la década del sesenta. Buenos Aires: Puntosur.

Tarcus, H. (2001, 8 de julio). "Las caricaturas del joven Copi”. Clarín. pp. 8-9. 